\title{
Environmental variability as a factor controlling spatial patterns in distribution and species diversity of zooplankton in the St. Lawrence Estuary*
}

\author{
Réjean Laprise, Julian J. Dodson \\ Département de Biologie, Université Laval, Sainte-Foy, Québec, Canada G1K 7P4
}

\begin{abstract}
Field studies on a variety of organisms have suggested that environmental variability plays a major role in determining spatial patterns in distribution and species diversity of estuarine organisms due to the effect of abiotic fluctuations on the physiology of animals. However, there is no study examining the effect of environmental variability on zooplankton distribution and diversity in estuaries. As vertical migration is obligatory behavior for the retention of planktonic animals at intermediate positions in the St. Lawrence Estuary (Canada), vertical stratification of the water column is considered the major source of environmental variability for zooplankton in this system. To evaluate the importance of this source of variability as a factor controlling the distribution and diversity of zooplankton in the estuary, we examined the relative contribution of each of the environmental factors of salinity, temperature, turbidity and vertical stratification in explaining spatial patterns of summer zooplankton distribution and diversity. Multivariate analyses revealed the presence of a longitudinal succession of seasonally stable species assemblages (tidal freshwater, true-estuarine and euryhalinemarine assemblages) whose spatial distribution was mainly a function of salinity and vertical stratification. Turbidity and temperature played a minor role in explaining spatial distribution. For all sampling periods, the limit between the true-estuarine and euryhaline-marine assemblages, the lowest number of population centers and the lowest zooplankton abundance all corresponded to the most vertically stratified waters. In contrast, population centers of all species were concentrated in the most abiotically stable parts of the estuary. We conclude that environmental variability is a major factor determining zooplankton distribution and diversity in the estuary. The spatio-temporal stability of the species assemblages and the seasonal variability in the abundance of some species also suggest that trophic interactions may play an important role in the regulation of zooplankton populations in the estuary.
\end{abstract}

KEY WORDS: Zooplankton assemblages S Salinity · Turbidity $\cdot$ Temperature $\cdot$ Spatio-temporal structure

\section{INTRODUCTION}

It is widely accepted that estuarine ecosystems are variable environments compared to the more stable limnic and marine ecosystems (Green 1968, Kinne 1971, Remane \& Schlieper 1971, McLusky 1981). High and rapid fluctuations in abiotic parameters such as salinity and temperature may be experienced by indi-

\footnotetext{
- Contribution to the programme of GIROQ/Groupe Interuniversitaire de Recherches Océanographiques du Québec)
}

vidual animals when moving against spatial gradients which are present on both horizontal and vertical axes of the environment (Laprise \& Dodson 1993). These fluctuations represent major physiological problems for animals. Osmotic and thermic stresses cause changes in basal metabolic rate, resulting in the reduction of surplus energy available for other activities such as locomotion, growth, reproduction and, ultimately, survival (Parry 1966, Holliday 1971, Kinne 1971, Vernberg \& Vernberg 1972). Several studies have demonstrated that this environmental variability plays a 
major role in determining spatial patterns of distribution and species diversity of estuarine animals (e.g. Sanders 1969, Heerebout 1970, De Jonge 1974). However, no such assessment has been made in the case of zooplankton.

For zooplankton in estuaries, migrating in a vertical gradient is the principal mechanism generating environmental variability (Laprise \& Dodson 1993). The magnitude and frequency of abiotic fluctuations experienced by individuals depend on 2 factors: the presence of vertical gradients and the vertical migratory behavior of animals. Vertically well-mixed waters constitute abiotically stable habitats. Vertically stratified waters are abiotically variable habitats except for animals which do not migrate vertically and thus do not experience large environmental fluctuations in the vertical axis.

We have proposed that vertical stratification influences the distribution and species diversity of estuar. ine zooplankton in cases where vertical migration is necessary to remain within the estuary because of hydrodynamic constraints (Laprise \& Dodson 1993). Such a situation occurs in the middle St. Lawrence Estuary, in eastern Canada. Circulation is characterized by a residual upstream displacement of salt water near the bottom that compensates for the downstream flow of fresh water at the surface (Ouellet \& Cerceau 1976). Transport studies on planktonic animals have demonstrated that individuals remaining in surface waters are transported downstream (Fortier \& Leggett 1982) whereas those that remain in deep waters accumulate at the head of the estuary (Laprise \& Dodson 1989, 1990). Consequently, migration in the vertical shear of current speed and direction constitutes the principal mechanism allowing retention of animals at intermediate positions in this estuary (Laprise \& Dodson 1993).

The zooplankton of the St. Lawrence Estuary is typical of large estuaries of the Northern Hemisphere (Runge \& Simard 1990). Three zooplankton assemblages have been identified and their spatial distribution has been related to salinity, temperature, turbidity and circulation. First, a euryhaline-marine assemblage is found near and downstream of lle aux Coudres, in the cold, saline, and deep waters flowing in an upstream direction (see review by Runge \& Simard 1990; Fig. 1). A second assemblage, composed of euryhaline species endemic to the estuary, is dominant in the warmer, less saline and turbid well-mixed waters located between lle d'Orléans and lle aux Coudres (Bousfield et al. 1975, Dodson et al. 1989). The distribution of this assemblage as a whole has been related to the presence of a maximum turbidity zone observed at the head of the estuary, where organisms accumulate passively as does suspended particulate matter (SPM) due to estuarine circulation (Dodson et al. 1989). Finally, freshwater species appear to dominate tidal fresh waters upstream of Ile d'Orléans (Bousfield et al. 1975).

However, as for other large estuaries, the spatio-temporal distribution of zooplankton with respect to abiotic factors in the St. Lawrence is poorly documented (Miller 1983, Runge \& Simard 1990). Upstream of Ile aux Coudres, Bousfield et al. (1975) only described the average (over $4 \mathrm{mo}$ ) longitudinal and vertical summer distribution of mesozooplankton (mostly copepods) in the Northern Channel. Dodson et al. (1989) described vertical distribution of macrozooplankton (mainly mysids, amphipods and euphausiids) at 3 stations along the Middle Channel only for the last week of July. Information on the tidal freshwater assemblage is virtually nonexistent and no study has examined the relationships between zooplankton distribution, species diversity and vertical stratification.

The major objective of this study is to evaluate the importance of variability in physico-chemical conditions in the vertical plane as a factor controlling the distribution and the diversity of zooplankton in the middle St. Lawrence Estuary. We examined the relative contribution of each of the environmental factors of salinity, temperature, SPM concentration and vertical stratification in explaining spatial patterns of zooplankton distribution and species diversity in the estuary. In addition, we document zooplankton assemblage structure in parts of the estuary and during periods of time never before sampled to ascertain how season and location within the estuary influence assemblage structure, and to provide a more detailed spatio-temporal description of zooplankton species distribution and abundance with respect to abiotic factors.

\section{MATERIAL AND METHODS}

Sampling. Thirty-seven stations were sampled at low and high slack waters $( \pm 1 \mathrm{~h})$ on 4 occasions in 1987: 3 to 8 June, 18 to 23 June, 3 to 8 July, and 18 to 23 July (Fig. 1). At each station, macrozooplankton was sampled using a double pelagic Tucker trawl (1.09 $\times$ $1.19 \mathrm{~m}$ ) equipped with two $0.5 \mathrm{~m}$ standard plankton nets $(0.51 \mathrm{~mm}$ mesh), which was towed in step-oblique fashion from the surface to $2 \mathrm{~m}$ from the bottom. In addition, 2 vertical tows of a $0.5 \mathrm{~m}$ standard net (0.063 $\mathrm{mm}$ mesh) were made from $2 \mathrm{~m}$ above the bottom to the surface to sample mesozooplankton. In total, 442 and 436 samples were collected with the Tucker trawl and standard net, respectively. Salinity and temperature profiles were carried out from the surface to $2 \mathrm{~m}$ above the bottom at each station. SPM concentration was measured at the surface and at $2 \mathrm{~m}$ from the 
bottom. Organisms were preserved in $4 \%$ buffered formaldehyde. Salinity, temperature and turbidity characteristics of the estuary as well as ichthyoplankton distribution were presented in detail by Laprise \& Dodson (1989).

Sample treatment. The spatio-temporal distribution of macrozooplankton in the estuary was assessed using all organisms collected by the Tucker trawl. The largest samples were split using a Motoda splitter (Van Guelpen et al. 1982). All organisms but amphipods, isopods and decapod larvae were identified to the species level. The great majority of amphipods captured were gammarids. Large adult calanoid copepods Calanus finmarchicus and $C$. hyperboreus were grouped in the taxon Calanus spp. Abundances of animals in each net were standardized for $100 \mathrm{~m}^{3}$. A mean abundance was calculated from the 2 samples collected by the double Tucker trawl at each station.

Spatial distribution of the poorly di-

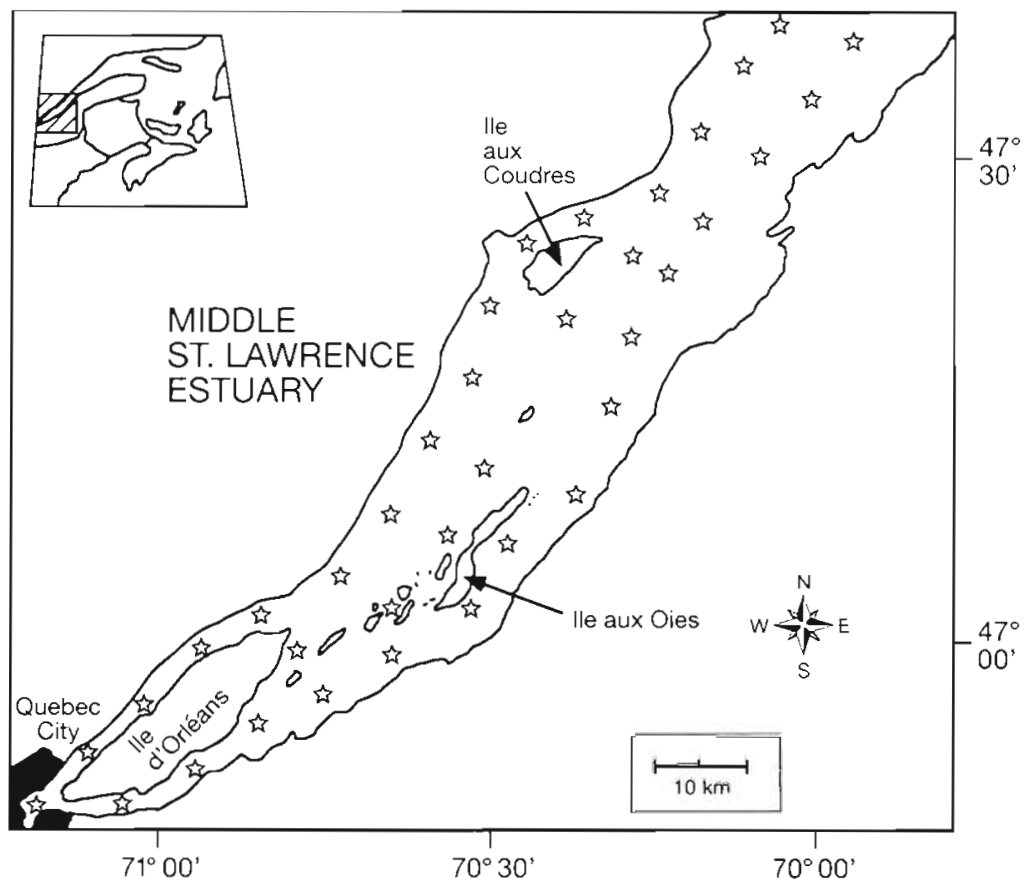

Fig. 1. Middle St. Lawrence Estuary, Canada and the location of the stations sampled in June and July 1987 versified mesozooplankton assemblages of the St. Lawrence Estuary can mostly be characterized by their highly dominant species, consisting of Bosmina longirostris, Eurytemora affinis and Calanus spp. for the freshwater, true-estuarine and euryhalinemarine assemblages, respectively (Bousfield et al. 1975). We chose to use these species as indicators of the relationship between mesozooplankton and environmental factors. Calanus spp. were well sampled by the Tucker trawl. The abundances of $B$. longirostris and $E$. affinis were evaluated semi-quantitatively from the standard net samples, using a logarithmic scale. This method gives results comparable to those obtained by traditional sorting methods while reducing the time and expense of processing samples (Frontier 1969). Each sample was stirred and an aliquot was taken using a Stempel pipette (Van Guelpen et al. 1982). The volume subsampled was adjusted to represent $1 \mathrm{~m}^{3}$ of water filtered by the net. This subsample was centrifuged to concentrate organisms in a smaller volume. No organisms were found in the supernatant and centrifugation did not damage them. The concentrate was examined under a binocular microscope in a $2 \mathrm{~cm}^{2}$ cell. For each species, the following scores were given: (1) no individuals, (2) 1 to 10 , (3) 11 to 100 , (4) 101 to 1000, (5) 1001 to 10000 . The subsample was then mixed again with the original sample and another subsample taken for a second evaluation. A regression between estimated scores and scores assigned after a traditional sorting of the samples revealed that the method gave a reliable estimation of the abundance of B. longirostris $\left(b=0.11, a=1.01, \mathrm{R}^{2}=0.93, \mathrm{p}<0.0001\right.$, $\mathrm{n}=60$ ). In the case of $E$. affinis, low abundances were slightly over-estimated whereas high abundances were slightly under-estimated $\left(b=0.42, a=0.88, \mathrm{R}^{2}=\right.$ $0.74, p<0.0001, n=60)$. However, residuals were uniformaly distributed along the scale of abundance which indicates that the bias was constant. Therefore, the method allows direct comparison between all samples. The 2 scores given to each of the 2 samples collected at each station were averaged.

Data analysis. Multivariate analyses were carried out to objectively identify zooplankton species assemblages in the estuary, to describe the spatio-temporal variability in their structure, and to examine the relative contribution of each environmental variable in explaining this structure. Analyses were conducted for each sampling period separately, using only stations where both Tucker and standard net samples were collected. The abundance of organisms did not change significantly between low and high slack waters for any given sampling period. Each sample was first described by 10 biological variables consisting of the abundance of 10 taxonomic groups of zooplankton (see Table 1). Abundances of species captured by the Tucker trawl were log transformed. Isopods and shrimp larvae were not included in the analysis due to their low occurence. These variables were used to construct a $\chi^{2}$ similarity matrix (Legendre \& Legendre 
1984). Using this measure of association, differences between the most abundant species contribute more to the similarity between samples than do differences between the rarer species. The hierarchical agglomerative clustering model of Lance \& Williams (1967; flexible grouping with $\alpha_{1}=0.5, \alpha_{m}=0.5, \beta=-0.25$ and $\gamma=0.0$ ) was carried out to group samples into homogeneous clusters. Clusters were then superimposed on a projection in the reduced plane of the first 2 axes of a principal coordinate analysis in order to separate groups with similar planktonic composition. These 3 steps were done using $\mathrm{R}$ software on a Macintosh (Legendre \& Vaudor 1991). Spearman correlations were calculated between principal axes and original data to identify species that contributed the most to the formation of each group of samples (Legendre \& Legendre 1984). Finally, multivariate discriminant analyses were conducted to separate the groups on the basis of environmental variables, including salinity (averaged for each vertical profile of the water column), surface SPM concentration and vertical stratification. Bottom SPM concentration and temperature were not used in these analyses because both were strongly correlated with either surface SPM concentration or salinity in the estuary (Laprise \& Dodson 1989). Vertical stratification was calculated as follows: differences between bottom and surface salinities $(\Delta S)$ were divided by the depth $Z$ of each station producing average rates of change of salinity per meter of depth. This ratio $(\Delta S / Z)$ gives a measure of the fluctuations in salinity (as well as temperature) animals experience while undertaking vertical migrations in the water column and allows comparison between stations of different depths (Laprise \& Dodson 1993).

The geographic distribution of each group revealed by the multivariate analyses was mapped for both low and high slack waters of each sampling period to examine the effect of tidal and seasonal variability of the estuarine circulation on the spatial distribution of zooplankton in the estuary.

A direct gradient analysis was performed to document the relationships between the distribution of each zooplankton species and environmental gradients (Gauch 1982). Abundance of each species was plotted as a function of the average salinity of the water column, $\Delta S / Z$ and surface SPM concentration.

Two indices were used to examine patterns of zooplankton species diversity along the estuarine gradient. First, species richness, $R$ (= number of species collected in samples; Pielou 1975), was estimated for 4 strata of average salinity: <1, between 1 and 10 , between 11 and 20, and $>20 \%$. However, planktonic animals are subjected to advective transport and individuals may be carried away from the areas where the species completes its life cycle. Hence, a significant proportion of some samples may consist of moribund, non-reproductive animals that drift along with dominant currents and find themselves in extreme environments (Bousfield et al. 1975). Therefore, indices of diversity based only on identification of the number of species occuring in samples (such as $R$ ) may give a distorted picture of the species carrying capacity of the environment in the case of zooplankton. To address this problem, we accounted for the abundance of individual species in the calculation of a new index of species diversity. $P$ (= number of population centers occurring in samples) was evaluated for the same salinity strata as used to calculate $R$. A salinity stratum was considered the population center of a species when it contained the bulk of the abundance of a given species. Taxa not identified to species during sorting were not included in the calculations of $R$ and $P$; these are amphipods, isopods and decapod larvae. Crangon septemspinosa was also excluded because this species is usually benthic and is only occasionally present in the plankton.

In order to increase confidence in the values of $P$ and $R$ as representative of the entire zooplankton community, both indices were also calculated by combining the results of this study with those of Bousfield et al. (1975; average salinity: Fig. 4, p. 331; species distributions: Table 1, p. 346-347; stations used: 13 , $51,76,77,80,81,83,84)$. The 2 data sets are directly comparable as both studies documented the distribution of species' abundance as a function of the longitudinal salinity gradient. The data set of Bousfield et al (1975) documents the distribution of different species using different sampling techniques (450 l of water pumped into a standard Clarke-Bumpus net of $64 \mu \mathrm{m}$ mesh size) to those employed in the present study. Four species (Ectinosoma cuticorne, Eurytemora herdimani, Acartia clausi and A. longiremis) were added to the 11 species sampled in the present study. Five species (Bosmina longirostris, Eurytemora affinis, Neomysis americana, Calanus finmarchicus and $C$. hyperboreus) were sampled in both studies and exhibited the same patterns of distribution and abundance with respect to salinity.

\section{RESULTS}

\section{Zooplankton assemblages}

The first 2 axes of the principal coordinate analysis explained between 75 and $79 \%$ of the total variance in species composition and abundance of zooplankton in the estuary (Table 1). The clustering procedure revealed that samples could be classified into 3 major groups for each sampling period. The superposition of 
Table 1. Zooplankton in the St. Lawrence Estuary, 1987. Spearman correlation coefficients, $r$, between zooplankton taxa and the first 2 axes of the principal coordinate analyses. Underlined coefficients are significant at $p \leq 0.05$. \% of variance refers to the percentage of total variance in species composition and abundance explained by Axes I and II

\begin{tabular}{|c|c|c|c|c|c|c|c|c|}
\hline \multirow{3}{*}{$\begin{array}{r}\text { Date: } \\
\text { Axis: } \\
\% \text { of variance: }\end{array}$} & \multicolumn{2}{|c|}{ June 3-8 } & \multicolumn{2}{|c|}{ June 18-23 } & \multicolumn{2}{|c|}{ July $3-8$} & \multicolumn{2}{|c|}{ July 18-23 } \\
\hline & I & II & I & II & I & II & I & II \\
\hline & 58 & 21 & 55 & 24 & 51 & 24 & 48 & 30 \\
\hline Bosmina longirostris & 0.88 & 0.17 & 0.90 & 0.28 & $\underline{0.85}$ & 0.15 & 0.83 & -0.05 \\
\hline Amphipods & $\underline{0.73}$ & -0.19 & $\underline{0.43}$ & 0.07 & $\underline{0.67}$ & 0.14 & $\underline{0.55}$ & -0.21 \\
\hline Eurytemora affinis & $\underline{0.29}$ & $-\underline{0.40}$ & -0.23 & $-\underline{0.59}$ & $-\underline{0.29}$ & -0.23 & 0.11 & 0.12 \\
\hline Neomysis americana & $\underline{0.52}$ & $-\underline{0.77}$ & -0.04 & $-\underline{0.88}$ & -0.26 & $-0 . \underline{94}$ & -0.49 & $\underline{0.84}$ \\
\hline Mysis stenolepis & $\underline{0.46}$ & $-\underline{0.82}$ & $-\underline{0.50}$ & $-\underline{0.88}$ & $-\underline{0.44}$ & $-\underline{0.87}$ & -0.49 & $\underline{0.72}$ \\
\hline Crangon septemspinosa & -0.10 & $-\underline{0.45}$ & $-\underline{0.53}$ & $-\underline{0.66}$ & $-\underline{0.44}$ & $-\underline{0.66}$ & $-\underline{0.50}$ & $\underline{0.64}$ \\
\hline Calanus spp. & $-\underline{0.84}$ & -0.08 & $-\underline{0.85}$ & 0.09 & $-\underline{0.86}$ & 0.04 & -0.84 & 0.27 \\
\hline Mysis littoralis & $-\underline{0.83}$ & -0.05 & $-\underline{0.67}$ & 0.01 & $-\underline{0.50}$ & 0.07 & $-\underline{0.33}$ & -0.05 \\
\hline Euphausiids & $-\underline{0.83}$ & 0.12 & $-\underline{0.73}$ & 0.23 & $-\underline{0.69}$ & 0.11 & $-\underline{0.63}$ & $-\underline{0.42}$ \\
\hline Sagitta elegans & $-\underline{0.87}$ & 0.06 & $-\underline{0.81}$ & 0.20 & $-\underline{0.77}$ & 0.07 & $-\underline{0.73}$ & $-\underline{0.46}$ \\
\hline No. of stations & \multicolumn{2}{|c|}{54} & \multicolumn{2}{|c|}{52} & \multicolumn{2}{|c|}{55} & \multicolumn{2}{|c|}{54} \\
\hline
\end{tabular}

these groups of samples on the reduced plane of the first 2 axes of the principal coordinate analysis showed that the first axis mainly separated Groups I and II from Group III while the second axis contributed to separate Groups I and II (Fig. 2). Samples of Groups I and II formed denser clusters than those of Group III, indicating that the taxonomic composition of samples of Group III was more heterogeneous. Zooplankton composition in samples of this group varied gradually from one station to the next.

Zooplankton taxa that contributed most to the formation of the first 2 axes were the same for all sampling periods. Spearman correlations (Table 1) indicate that the first axis mainly contributed to separate stations characterized by the highest abundances of Bosmina longirostris and amphipods from those containing the highest abundances of Calanus spp., Mysis littoralis, euphausiids (Thysanoessa inermis, $T$. longicaudata and Meganyctiphanes norvegica) and chaetognaths (Sagitta elegans). The second axis mainly contributed to separate stations characterized by the highest abundances of Neomysis americana, Mysis stenolepis, Crangon septemspinosa and Eurytemora affinis from the others.

Taxa characteristic of each group identified by the analysis, and the relative abundance of each species within each group, remained largely the same over the 2 months of the study, indicating that the species composition and the structure of zooplankton assemblages in the estuary were stable over this period (Table 2). For all sampling periods, Bosmina longirostris and amphipods reached highest abundances in samples of Group I, Neomysis americana, Mysis stenolepis and Eurytemora affinis in Group II, and Calanus spp., $M$.
Fig. 2. Zooplankton in the St. Lawrence Estuary, 1987: simultaneous projection of samples and groups of samples (I, II and III) on the first 2 axes of a principal coordinate analysis for each sampling period. Clustering of stations was obtained by the hierarchical agglomerative clustering model of Lance \& Williams (1967). Groups were formed at the similarity level of 0.98 for the period between June 3 and 8 and 0.97 for other sampling periods

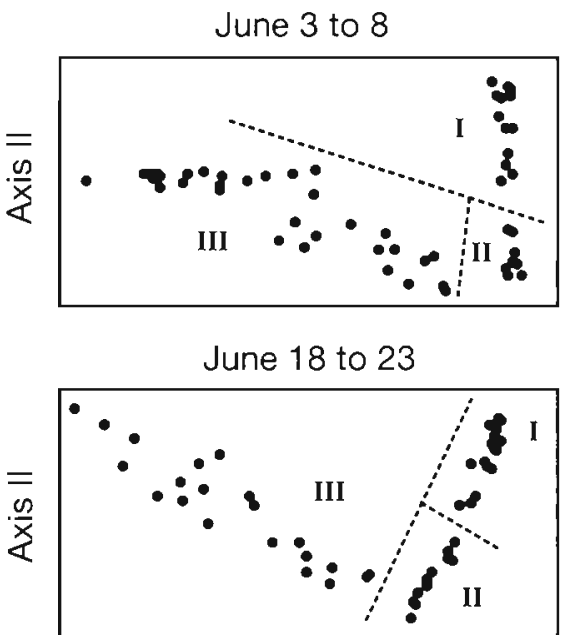

Axis I

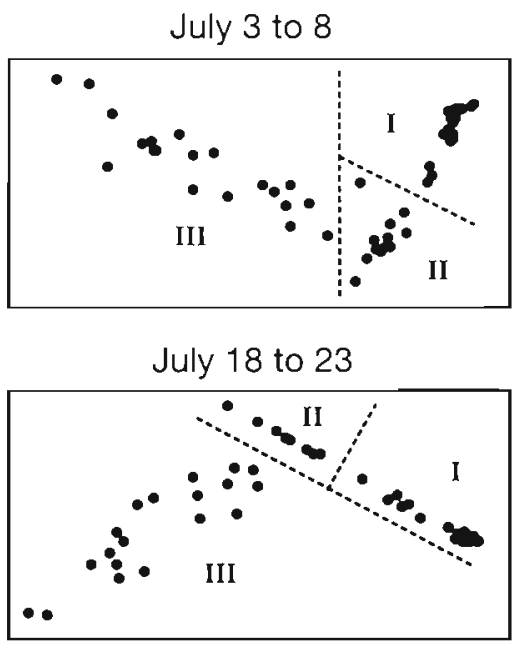

Axis I 
Table 2. Zooplankton in the St. Lawrence Estuary, 1987: mean abundance (standard deviation) of each taxon in the 3 groups of samples defined by the multivariate analyses. Abundances are in numbers of individuals per $100 \mathrm{~m}^{3} \mathrm{for}$ all species except Bosmina longirostris and Eurytemora affinis. In the case of these 2 species, means were calculated using scores of abundance estimated for $1 \mathrm{~m}^{3}$ (see text). Scores: (1) no individuals, (2) 1 to 10, (3) 11 to 100 , (4) 101 to 1000 and (5) $>1000$ individuals. Example: an average of 4.9 for $B$. longirostris in Group I is equivalent to between 101 and 1000 individuals per cubic meter (or $10^{4}$ to $10^{5}$ individuals per $100 \mathrm{~m}^{3}$ ). The group with the highest value for a given taxon is in bold type

\begin{tabular}{|c|c|c|c|}
\hline & Group: & II & III \\
\hline \multicolumn{4}{|l|}{ June 3 to 8} \\
\hline Bosmina longirostris & $4.9(0.3)$ & $4.5(0.5)$ & $1.7(1.0)$ \\
\hline Amphipods & $37.5(42.6)$ & $23.4(22.5)$ & $8.5(16.6)$ \\
\hline Eurytemora affinis & $3.5(0.7)$ & $3.9(0.9)$ & $3.3(1.0)$ \\
\hline Neomysis americana & $0.7(1.1)$ & $1795.7(2276.4)$ & $128.7(286.3)$ \\
\hline Mysis stenolepis & $1.7(4.9)$ & $442.0(513.4)$ & $85.7(190.5)$ \\
\hline Calanus spp. & 0 & 0 & $339.8(626.6)$ \\
\hline Mysis littoralis & 0 & 0 & $32.1(71.0)$ \\
\hline Sagitta elegans & 0 & 0 & $4.2(7.6)$ \\
\hline Thysanoessa longicaudata & 0 & 0 & $2.7(8.4)$ \\
\hline Thysanoessa inermis & 0 & 0 & $2.4(7.2)$ \\
\hline Crangon septemspinosa & 0 & $0.01(0.02)$ & $0.4(1.0)$ \\
\hline Meganyctiphanes norvegica & 0 & 0 & $0.2(0.5)$ \\
\hline Penaeid larvae & 0 & 0 & $0.1(0.3)$ \\
\hline Isopods & 0 & 0 & $0.01(0.04)$ \\
\hline No. of stations & 13 & 8 & 33 \\
\hline \multicolumn{4}{|l|}{ June 18 to 23} \\
\hline B. Iongirostris & $5.0(0.1)$ & $4.2(0.8)$ & $1.7(0.9)$ \\
\hline Amphipods & $56.4(67.4)$ & $37.2(48.7)$ & $9.2(10.0)$ \\
\hline E. affinis & $3.1(0.4)$ & $4.0(0.7)$ & $3.6(0.9)$ \\
\hline N. americana & $1.3(2.5)$ & $2018.0(1185.0)$ & $142.0(433.5)$ \\
\hline M. stenolepis & $0.2(0.4)$ & $175.1(196.9)$ & $45.1(97.2)$ \\
\hline Calanus spp. & 0 & $0.01(0.02)$ & 610.5 (1614.9) \\
\hline M. littoralis & 0 & 0 & $4.9(10.4)$ \\
\hline T. inermis & 0 & 0 & $1.9(6.8)$ \\
\hline S. elegans & 0 & 0 & $1.1(2.6)$ \\
\hline C. septemspinosa & 0 & $0.4(0.5)$ & $0.6(0.7)$ \\
\hline T. longicaudata & 0 & 0 & $0.1(0.4)$ \\
\hline M. norvegica & 0 & 0 & $0.1(0.3)$ \\
\hline Isopods & 0 & 0 & $0.02(0.08)$ \\
\hline No. of stations & 18 & 13 & 21 \\
\hline \multicolumn{4}{|l|}{ July 3 to 8} \\
\hline B. Jongirostris & $4.4(0.6)$ & $3.7(0.7)$ & $1.5(0.7)$ \\
\hline Amphipods & $128.3(249.7)$ & $29.6(27.4)$ & $6.1(10.4)$ \\
\hline E. affinis & $3.1(0.5)$ & $3.7(1.0)$ & $3.4(0.7)$ \\
\hline N. americana & $5.5(13.8)$ & $3046.6(1901.7)$ & $128.7(336.4)$ \\
\hline$M$. stenolepis & $0.07(0.2)$ & $238.2(365.4)$ & $57.0(206.4)$ \\
\hline C. septemspinosa & 0 & $1.1(2.0)$ & $0.2\{0.4\}$ \\
\hline Calanus spp. & 0 & 0 & $462.3(667.6)$ \\
\hline M. littoralis & 0 & 0 & $2.8(7.5)$ \\
\hline S. elegans & 0 & 0 & $2.0(3.1)$ \\
\hline T longicaudata & 0 & 0 & $0.8(2.3)$ \\
\hline T. inermis & 0 & 0 & $0.2(0.3)$ \\
\hline M. norvegica & 0 & 0 & $0.02(0.1)$ \\
\hline Isopods & 0 & 0 & $0.02(0.1)$ \\
\hline No. of stations & 22 & 12 & 21 \\
\hline \multicolumn{4}{|l|}{ July 18 to 23} \\
\hline B. longirostris & $4.5(0.6)$ & $2.6(1.1)$ & $1.2(0.5)$ \\
\hline Amphipods & $162.2(188.0)$ & $17.6(30.2)$ & $7.8(11.0)$ \\
\hline E. affinis & $3.6(0.6)$ & $3.7(0.4)$ & $3.1(0.6)$ \\
\hline N. americana & $65.9(189.5)$ & $6870.6(7623.0)$ & $212.3(449.2)$ \\
\hline M. stenolepis & 0 & $217.8(178.5)$ & $12.4(26.7)$ \\
\hline C. septemspinosa & 0 & $1.1(1.3)$ & $0.2(0.3)$ \\
\hline Calanus spp. & 0 & 0 & $219.4(318.4)$ \\
\hline S. elegans & 0 & 0 & $0.9(2.2)$ \\
\hline$T$. inermis & 0 & 0 & $0.7(1.0)$ \\
\hline T. longrcaudata & 0 & 0 & $0.6(1.6)$ \\
\hline M. littoralis & 0 & 0 & $0.3(0.9)$ \\
\hline M. norvegica & 0 & 0 & $0.2(0.5)$ \\
\hline Isopods & 0 & 0 & $0.04(0.1)$ \\
\hline No. of stations & 27 & 8 & 19 \\
\hline
\end{tabular}


littoralis, Sagitta elegans and the euphausiids in Group III. Crangon septemspinosa was more abundant in Group III in June and in Group II in July. Isopods and penaeid larvae were captured at stations of Group III only.

\section{Geographic distribution of zooplankton assemblages}

The geographic distribution of the samples in the St. Lawrence shows a well-defined longitudinal array of the zooplankton assemblages defined in our analysis (Fig. 3). In the northern channel, the first assemblage of species (Group I) was associated with the upper estuary, in the vicinity and upstream of Ile d'Orléans. The second assemblage (Group II) was associated with the area between Ile d'Orléans and lle aux Coudres, which corresponds to the upper part of the middle estuary. Finally, the third assemblage (group III) was associated with the lower part of the middle estuary, in the vicinity and downstream of Ile aux Coudres. The longitudinal position of the assemblages moved upstream and downstream according to tides as animals were advected by tidal currents (Fig. 3). There was also a lateral gradient in the distribution of zooplankton. The upstream limit of a given group was usually farther upstream in the northern channel of the estuary than in the others, an observation also noted for salinity, temperature and SPM concentration (Laprise \& Dodson 1989). This is mostly an effect of the Coriolis force on the circulation, which displaces water moving seawards to the south and east and water moving landward to the north and west, creating a skewed distribution in physical and biological variables.

\section{Assemblage distribution with respect to abiotic factors}

For all sampling periods, the first function of the discriminant analysis to separate zooplankton assemblages on the basis of physico-chemical characteristics of the stations explained more than $96 \%$ of the intergroup variability (Table 3 ). The values of standardized canonical coefficients indicate that the assemblages of species can mainly be characterized by salinity and, to a lesser extent, by $\Delta S / Z$. Except for the first sampling period in early June, turbidity was not correlated with the first canonical axis. Due to its high negative correlation with salinity for any sampling period (Pearson correlations: $-0.99 \leq \mathrm{r} \leq-0.93, \mathrm{p}<0.001$ ), temperature characterized zooplankton assemblages as well as salinity.

A discriminant analysis was also conducted on the 3 assemblages of species pooled for all sampling periods in order to separate the effects of temperature and
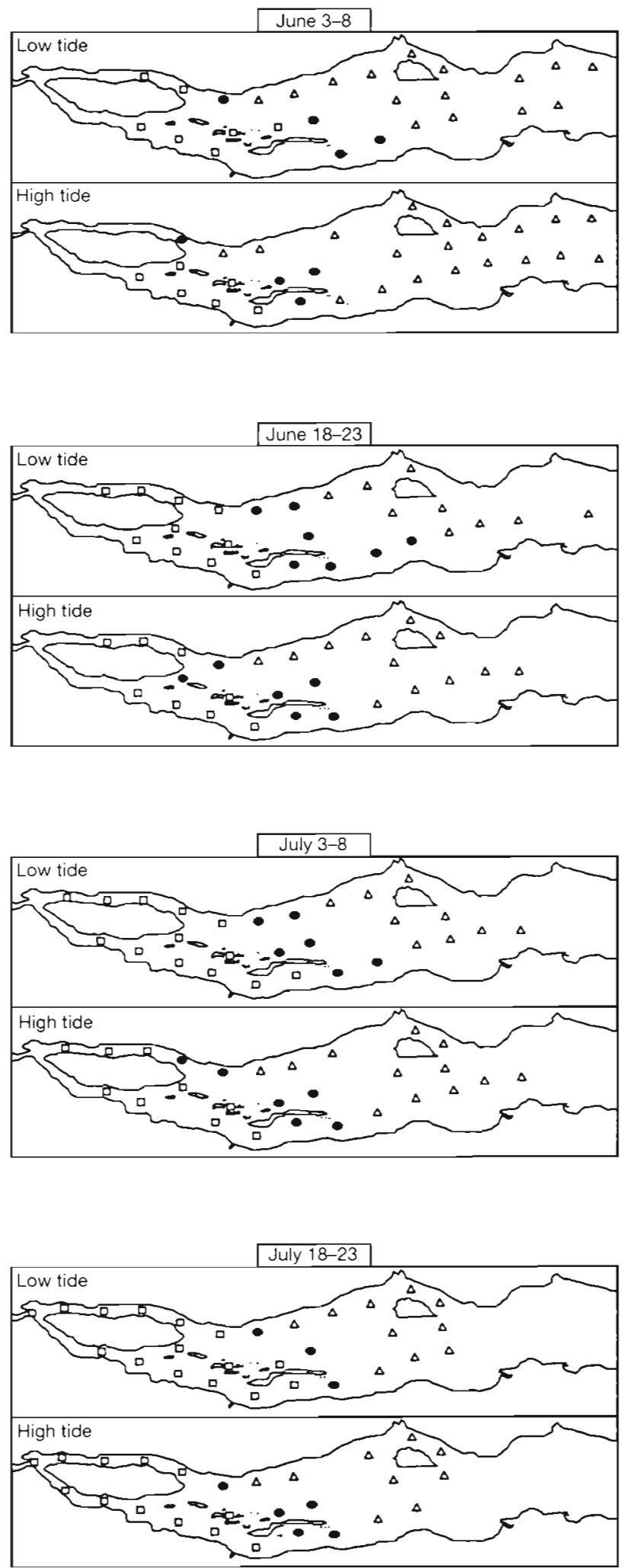

Fig. 3. Zooplankton in the St. Lawrence Estuary, 1987: geographical distribution of the species assemblages defined in Table 2 at low and high slack waters for each sampling period. Squares: Group I; circles: Group II; triangles: Group III 
Table 3. Zooplankton in the St. Lawrence Estuary, 1987: relative contribution of each physical variable (standardized canonical coefficients) to the formation of the first discriminant axis separating the groups of zooplankton defined by the multivariate analysis. Numbers in parenthesis indicate the importance of each variable by ascending order. \% of variance: percentage of variance explained by the first axis. Salinity and temperature: averages for the water column; SPM: surface concentrations of suspended particulate matter; $\Delta S / Z$ : vertical stratification in salinity

\begin{tabular}{|c|c|c|c|c|c|}
\hline $\begin{array}{r}\text { Date: } \\
\% \text { of variance: }\end{array}$ & $\begin{array}{c}\text { June } 3-8 \\
96.9\end{array}$ & $\begin{array}{c}\text { June } 18-23 \\
98.4\end{array}$ & $\begin{array}{c}\text { July } 3-8 \\
99.5\end{array}$ & $\begin{array}{c}\text { July } 1.8-23 \\
99.9\end{array}$ & $\begin{array}{c}\text { Pooled } \\
98.4\end{array}$ \\
\hline Salinity & $1.67\{1\}$ & $2.33(1)$ & $1.99(1)$ & $2.31(1)$ & $1.32(1)$ \\
\hline Temperature & - & - & - & - & $-0.74(3)$ \\
\hline SPM & $0.44(3)$ & $0.05(3)$ & $0.05(3)$ & $0.01(3)$ & $0.07(4)$ \\
\hline$\Delta S / Z$ & $1.13(2)$ & $0.90(2)$ & $1.19(2)$ & $1.63(2)$ & $1.23(2)$ \\
\hline Wilks' $\lambda(\mathrm{p}<0.0001)$ & 0.13 & 0.09 & 0.10 & 0.07 & 0.11 \\
\hline
\end{tabular}

salinity, as temperature in the estuary increased significantly during the season for all salinities (Tables 3 \& 4). The first canonical axis, which explained more than $98 \%$ of the variance between the groups, remained strongly correlated with salinity (Table 3 ). The variables $\triangle \mathrm{S} / Z$ and temperature were also correlated with the first axis but to a lesser extent. The signs of canonical coefficients reflect the relation between $\Delta S / Z$ and temperature with salinity, these variables co-varying in the sampling area: saline waters are always colder and more stratified than fresh waters. This analysis demonstrates that the relation between zooplankton assemblages and the longitudinal gradients of salinity and $\Delta S / Z$ remained stable over the 2 mo period of the study.
An examination of the physico-chemical characteristics of each assemblage reveals that the first assemblage of species was associated with the warm, wellmixed waters of salinity less than $1.6 \%$, the second assemblage with the colder, weakly stratified waters of salinities less than ca $8 \%$, and the third assemblage, with the coldest and most stratified waters of salinities higher than 5\% (Table 4). As such, these assemblages may be defined as the freshwater, true-estuarine and euryhaline-marine assemblages, respectively. Although zooplankton of Group II was generally found in more turbid waters than zooplankton of Groups I and III, some samples of Group I were characterized by very high turbidities which at times exceeded turbidities associated with Group II.

Table 4. Zooplankton in the St. Lawrence Estuary, 1987: average physico-chemical conditions [depth-averaged salinity and tem-

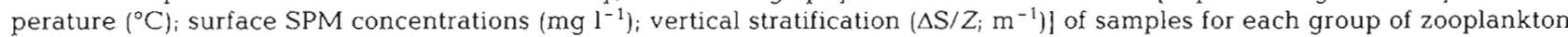
defined by the multivariate analysis. Ranges in parentheses

\begin{tabular}{|c|c|c|c|}
\hline & Group: & II & III \\
\hline \multicolumn{4}{|l|}{ June 3 to 8} \\
\hline Salinity & $0.1(0-0.6)$ & $1.6(0.6-4.1)$ & $21.4(5.1-33.4)$ \\
\hline Temperature & $16.2(15.2-16.9)$ & $14.8(13.1-16.3)$ & $6.4(1.7-12.4)$ \\
\hline SPM & $8.0(1.0-14.6)$ & $16.3(7.0-37.7)$ & $10.6(0.2-23.3)$ \\
\hline$\Delta \mathrm{S} / Z$ & $0.00(0.00-0.02)$ & $0.10(0.00-0.31)$ & $0.52(0.15-1.26)$ \\
\hline \multicolumn{4}{|l|}{ June 18 to 23} \\
\hline Salinity & $0.1(0.0-0.6)$ & $3.0(0.5-6.6)$ & $21.1(10.3-30.7)$ \\
\hline Temperature & $17.3(16.3-18.0)$ & $15.7(14.3-16.9)$ & $7.8(3.1-12.9)$ \\
\hline SPM & $22.9(2.8-72.6)$ & $32.3(14.7-63.1)$ & $13.3(8.0-30.3)$ \\
\hline$\Delta \mathrm{S} / Z$ & $0.00(0.00-0.01)$ & $0.13(0.00-0.31)$ & $0.41(0.07-0.71)$ \\
\hline \multicolumn{4}{|l|}{ July 3 to 8} \\
\hline Salinity & $0.0(0.0-0.5)$ & $3.4(1.0-8.2)$ & $19.4(10.0-29.3)$ \\
\hline Temperature & $19.0(18.2-19.9)$ & $16.8(15.2-17.9)$ & $9.3(4.8-13.7)$ \\
\hline SPM & $19.3(0.4-123.4)$ & $25.3(6.6-101.6)$ & $12.8(6.0-32.1)$ \\
\hline$\Delta \mathrm{S} / Z$ & $0.00(0.00-0.00)$ & $0.13(0.02-0.39)$ & $0.57(0.32-0.88)$ \\
\hline \multicolumn{4}{|l|}{ July 18 to 23} \\
\hline Salinity & $0.1(0.00-1.6)$ & $2.8(0.5-5.0)$ & $16.7(6.1-27.1)$ \\
\hline Temperature & $22.3(20.6-24.1)$ & $19.7(13.9-21.9)$ & $11.4(5.1-18.2)$ \\
\hline SPM & $17.4(4.9-78.5)$ & $19.9(14.4-26.5)$ & $11.2(5.8-19.7)$ \\
\hline$\Delta S / Z$ & $0.00(0.00-0.08)$ & $0.14(0.00-0.35)$ & $0.64(0.31-1.16)$ \\
\hline
\end{tabular}



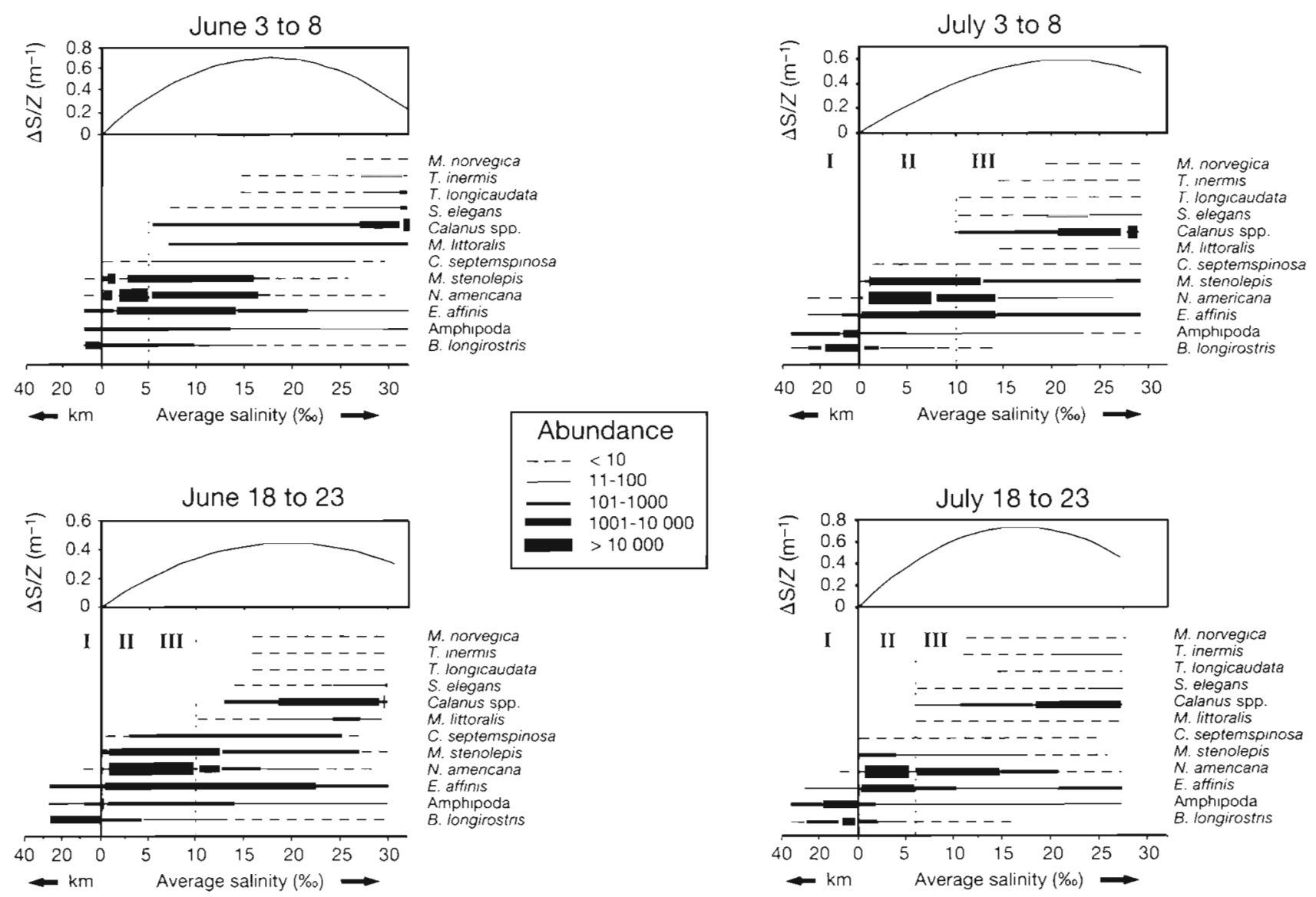

Fig. 4. Zooplankton in the St. Lawrence Estuary, 1987: distribution of each species with respect to the average salinity of the water column, the distance upstream of the salinity front $(\mathrm{km})$ and the average vertical stratification in salinity $(\Delta S / Z)$ for each sampling period. Abundances are on a logarithmic scale, for $100 \mathrm{~m}^{3}$ for all species but Eurytemora affinis and Bosmina longirostris which are for $1 \mathrm{~m}^{3}$. Details on regressions between $\Delta S / Z$ and average salinity are presented in Table 5. Plain vertical line: salinity front; dashed vertical line: limit between species Groups II and III defined in Tables $2 \& 4$. See Table 2 for full genus names

\section{Species distribution and diversity with respect to abiotic factors}

Salinity

Fig. 4 shows the relationships between each taxon and the average salinity of the water column in the estuary. In tidal fresh water, the distribution of each taxon is presented as a function of the upstream distance relative to the salinity front, which we defined as waters of salinity $0.5 \%$. The limits of distributions are approximate because their estimation depends on the location of samples along the salinity gradient and on the estimation of the position of the salinity front.

Taxa characteristic of the freshwater assemblage, Bosmina longirostris and amphipods, reached their maximum abundances upstream of the salinity front. Their abundance diminished rapidly as salinity increased. Both taxa occurred in the highest salinities except in the case of $B$. longirostris in July which dis- appeared in salinities higher than ca $15 \%$. Upstream of the salinity front, the variability in the abundance of these taxa was a function of the distance from the limit of salt-water intrusion. The abundances of $B$. longirostris and amphipods diminished significantly after ca $20 \mathrm{~km}$ upstream in the river. Although amphipods of this assemblage were not identified, it is most probable that Gammarus tigrinus accounted for most of them, as Dodson et al. (1989) found that this species was the only one caught in the most upstream section of the estuary using the same net.

Species characteristic of the true-estuarine assemblage reached their highest abundances in waters of salinities higher than $0.5 \%$ and lower than $10 \%$ except for Eurytemora affinis, which reached high abundances in salinities as high as ca $23 \%$ in June. The sharpest increase in the abundance of these species corresponded to the initial decline in the abundance of the species of the tidal freshwater assemblage. Mysids were seldom caught upstream of the salinity front 

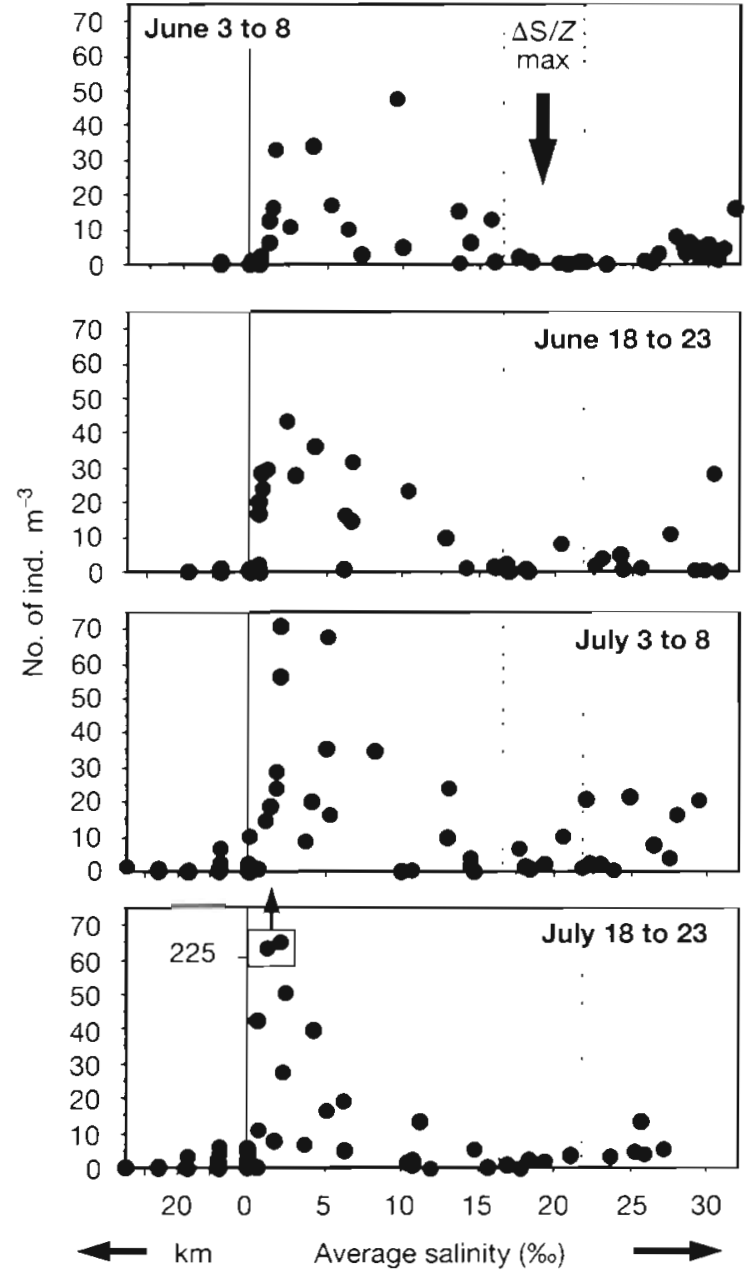

Fig. 5. Zooplankton in the St. Lawrence Estuary, 1987: total abundance of zooplankton captured with a Tucker trawl (500 $\mu \mathrm{m}$ mesh) with respect to average salinity of the water column, distance upstream of the salinity front $(\mathrm{km})$ and vertical stratification in salinity $(\Delta S / Z)$. Plain vertical line: salinity front. Dashed vertical lines: range of depth-averaged salinities coinciding with maximum values of $\Delta S / Z$

whereas $E$. affinis was common in these waters. All species of this assemblage were caught in waters of highest salinities. The range of salinity occupied by Mysis stenolepis became narrower as the season progressed, concomitantly with a reduction of their total abundance in the estuary. The distribution of $E$. affinis became bimodal at the end of July. During this period, there was a maximum in abundances in salinities less than $6 \%$, and another, lower maximum in salinities higher than $20 \%$. This maximum may be related to another closely related species, E. herdmani, known to occur in high salinities downstream of lle aux Coudres (Bousfield et al. 1975). We did not discriminate between these 2 species during sorting.

Taxa characteristic of the euryhaline-marine assemblage were not very abundant in the sampling area.

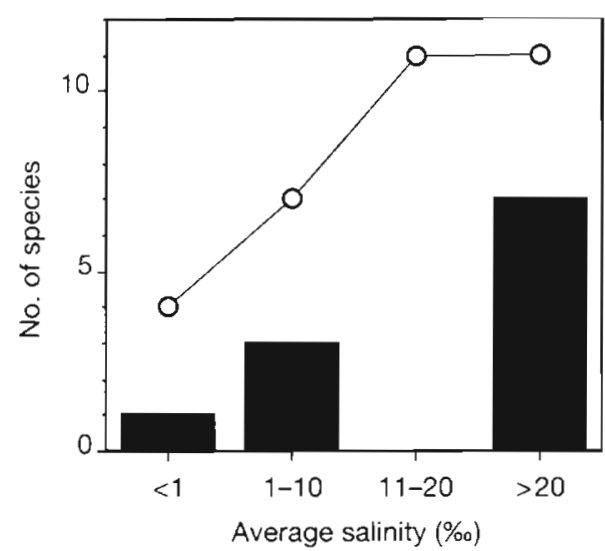

Fig. 6. Zooplankton diversity in the St. Lawrence Estuary, 1987: number of species (species richness, $R_{i}$ open symbols) and number of species exhibiting maximum population abundance (population richness, $P$; vertical bars) as a function of the average salinity of the water column

Their abundance steadily increased with salinity and always reached maximum in highest salinities. The upstream limit of Calanus spp., Sagitta elegans and Mysis littoralis was around salinities of $6 \%$ whereas euphausiids never occured in waters less than $10 \%$.

The total abundance of zooplankton captured with the Tucker trawl varied as a function of salinity in a fashion that was consistent for all sampling periods (Fig. 5). Highest abundances of large zooplankton were always found in salinities corresponding to the distribution of the true-estuarine assemblage. Abundances decreased sharply upstream in the river and downstream in the estuary, and minimum values were observed mainly between salinities of ca 15 and $25 \%$. Abundances increased again in waters of higher salinities largely due to the presence of Calanus spp. We are unable to determine the relationship between total abundance of mesozooplankton and salinity from our data as the abundance of only 2 species was evaluated from standard net samples.

Species diversity also varied as a function of average salinity. Species richness $(R)$ was lowest in tidal fresh waters and increased seaward (Fig. 6). The number of species' population centers $(P)$ also increased with salinity with the notable exception that no species exhibited maximum abundance in the 11 to $20 \%$ salinity stratum. Combining the present data set with that of Bousfield et al. (1975) revealed the same pattern for both $R$ and $P$ except that $R$ was greater in the 11 to $20 \%$ salinity stratum than in the most saline waters (Fig. 7).

\section{Vertical stratification $(\Delta \mathrm{S} / Z)$}

$\triangle S / Z$ varied significantly along the estuarine gradient as a function of the average salinity of the water 


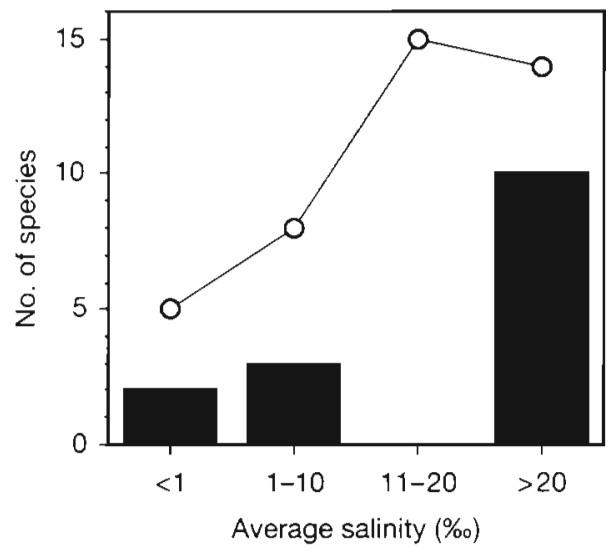

Fig. 7. Zooplankton diversity in the St. Lawrence Estuary: number of species (species richness, $R_{\text {; }}$ open symbols) and number of species exhibiting maximum population abundance (popu-

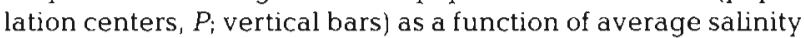
of the water column. Indices were calculated from the results of this study and those of Bousfield et al. (1975)

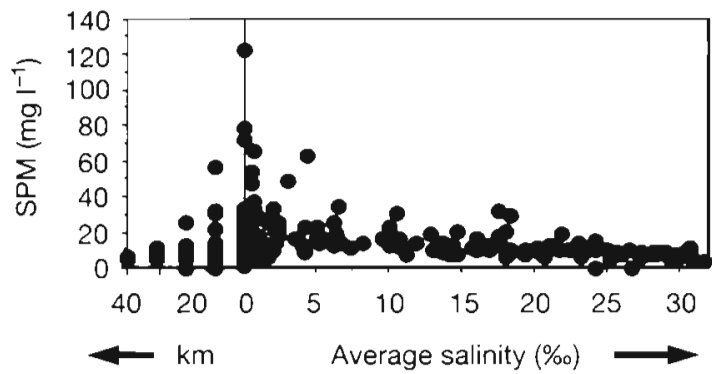

Fig. 8. Suspended particulate matter in the St. Lawrence Estuary, 1987: concentration in surface waters as a function of the average salinity of the water column and distance upstream of the salinity front $(\mathrm{km})$

column (Fig. 4, Table 5). Maximum stratification was reached in waters of salinities between 17 and $22 \%$.

The lowest abundances of all species collected in this study were associated with the highest values of $\Delta S / Z$ (Fig. 4). The depression in both total abundance of large zooplankton (Fig. 5) and number of population centers (Figs. $6 \&$ 7) also corresponded to the most vertically stratified waters in the estuary.

The salinity range occupied by the true-estuarine assemblage varied during the season as a function of the vertical stratification (Fig. 4). Vertical stratification in the estuary was on average higher early in June and late in July and lower late in June and early in July. The downstream limit of the true-estuarine assemblage along the salinity gradient was in higher salinities late in June and early in July when vertical stratification was low. The downstream limit of this assemblage was in lower salinities early in June and late in July when vertical stratification was greatest.
Table 5. Vertical stratification in the St. Lawrence Estuary, 1987: coefficient of determination $\left(R^{2}\right)$ of regressions presented in Fig. 4 describing the evolution of the vertical stratification in salinity $(\Delta S / Z)$ as a function of the average salinity of the water column $(\overline{\mathrm{S}})$. Model fitted: $\Delta \mathrm{S} / \mathrm{Z}=b_{0}+b_{1} \overline{\mathrm{S}}-b_{2} \overline{\mathrm{S}}^{2}$ Max.: average salinity $(\%)$ of the water column where the function reaches maximum

\begin{tabular}{|lcccc|}
\hline Date & $\mathrm{n}$ & $\mathrm{R}^{2}$ & $\mathrm{p}$ & Max. \\
\hline June 3 to 8 & 57 & 0.75 & 0.0001 & 18 \\
June 18 to 23 & 55 & 0.68 & 0.0001 & 19 \\
July 3 to 8 & 53 & 0.83 & 0.0001 & 22 \\
July 18 to 23 & 40 & 0.84 & 0.0001 & 17 \\
\hline
\end{tabular}

\section{SPM concentration}

No significant correlations between SPM concentrations and individual species abundances were found for the 4 sampling periods. Total abundance of large zooplankton and species diversity indices were not associated with maximum SPM concentrations. Maximum SPM concentrations were reached at the salinity front corresponding to the limit between the tidal freshwater and the true-estuarine assemblages (Fig. 8). Values decreased in both the upstream and downstream directions, the maximum turbidity zone (MTZ) extending into both tidal fresh waters and low salinity waters. As a result, both tidal freshwater and true-estuarine zooplankton assemblages were associated with the MTZ.

\section{Seasonal variability in abundance}

Seasonal variability in the abundance of some of the species characteristic of the tidal freshwater and trueestuarine assemblages is illustrated in Fig. 9. Seasonal variability in the abundances of euryhaline-marine species is not presented because they were captured at the upstream limit of their distribution and changes in their abundance may not be characteristic of the whole population. In the case of Crangon septemspinosa, the low abundance of this species in the water column is probably due to its benthic habits and cannot be considered representative of the population. For each species, we calculated the mean abundance of animals in the area comprised between $9 \mathrm{~km}$ upstream of the salinity front and salinities less than $25 \%$. This area contained most of the populations of the species characteristic of Groups I and II and was well sampled at all sampling periods. Each sample was assigned to a class of salinity as follows: $\leq 0.5 \%$; $>0.5 \%$ and $\leq 5 \%$; $>5 \%$ and $\leq 15 \% ;>15 \%$ and $\leq 25 \%$. Each salinity stratum was given a weight reflecting its size $(1,1,2$ and 2 , respectively) and averages were calculated as for a 

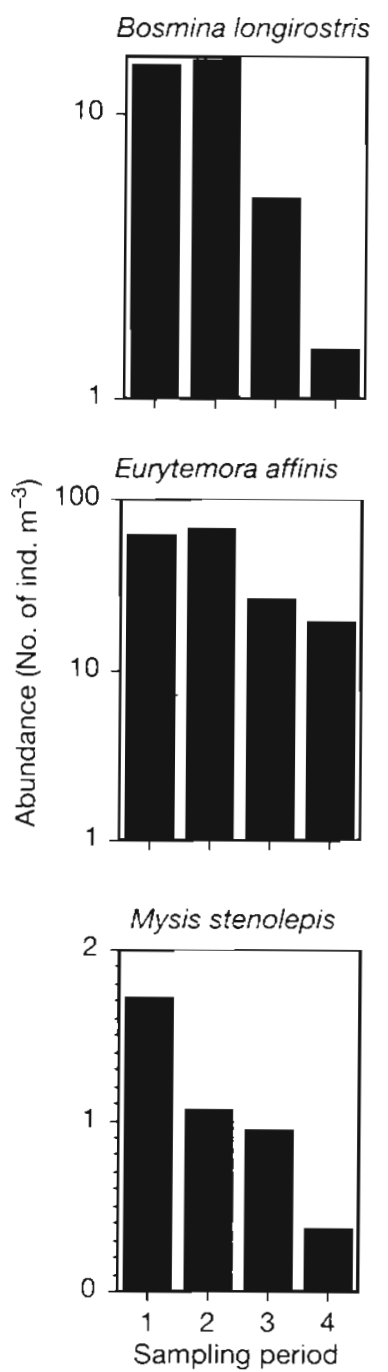

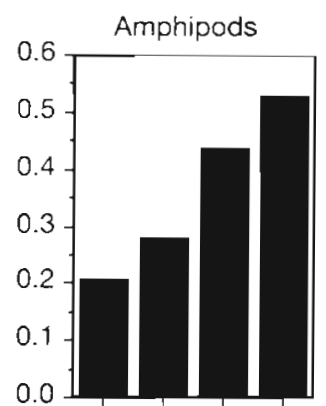

Neomysis americana

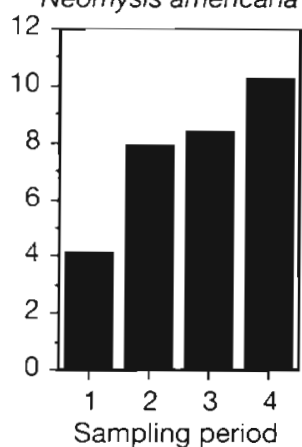

Fig. 9. Zooplankton in the St. Lawrence Estuary, 1987: seasonal variability in the abundance of some species. Sampling periods: (1) June 3 to 8 , (2) June 18 to 23 , (3) July 3 to 8 , (4) July 18 to 23

stratified random sampling (Frontier 1983). This improves the estimates as the distributions of all species were strongly associated with salinity. This poststratification of the samples allows a comparison between dates by eliminating biases created by the aggregation of samples in certain salinity values at a given sampling period. There were always 7 or more samples for each stratum.

Results indicate strong seasonal patterns in the abundance of zooplankton in the estuary. The average abundances of the 2 microcrustacean species, Bosmina longirostris and Eurytemora affinis, were highest in June. This was followed by a sharp decrease in July. The abundance of $B$. longirostris was reduced by 1 order of magnitude at the end of July compared to previous abundances in June whereas the abundance of E. affinis was reduced by $72 \%$. Mysis stenolepis also diminished in abundance as the season progressed, going from an average abundance of 172 per $100 \mathrm{~m}^{3}$ early in July to only 36 per $100 \mathrm{~m}^{3}$ at the end of July.

In contrast, the populations of the 2 dominant macrozooplankton taxa of the tidal freshwater and the trueestuarine assemblages increased regularly during the season; both Neomysis americana and amphipods were approximatly 2.5 times more abundant at the end of July than at the beginning of June. As such, abundance of mesozooplankton decreased significantly as the season progressed while abundance of macrozooplankton increased.

\section{DISCUSSION}

Multivariate analyses revealed the presence of a longitudinal succession of 3 well-defined zooplankton assemblages in the St. Lawrence Estuary. The species composition and the structure of these assemblages remained stable over the 2 mo sampling period. Variations in the geographic position of these assemblages over time were mainly a function of temporal variations in depth-averaged salinity. These results are consistent with studies that consider salinity the most important environmental variable determining geographical distributions of zooplankton in estuaries (e.g. Kinne 1971, Collins \& Williams 1981). A tidal freshwater assemblage dominated by Bosmina longirostris and an amphipod (probably Gammarus tigrinus) was found in the vicinity of Ile d'Orléans. Species of the tidal freshwater assemblage reached highest abundances just upstream of the limit of salt-water intrusion, suggesting that this assemblage was not characteristic of the whole tidal freshwater portion of the river, which stretches $150 \mathrm{~km}$ upstream of Ile d'Orléans, but of the area just beyond the salinity front. A true-estuarine assemblage composed mainly of Eurytemora affinis, Neomysis americana and Mysis stenolepis was characteristic of the area just downstream of Ile d'Orléans in salinities between 0.5 and 10 . Large zooplankton of this assemblage was the most abundant of the estuary. Finally, a euryhaline-marine assemblage composed of Calanus spp. (C. finmarchicus and C. hyperboreus), $M$. littoralis, euphausiids and chaetognaths was found downstream of the true-estuarine assemblage. Abundances of euryhaline-marine species increased with salinity, indicating that maximum abundances were reached downstream of the sampling area, in waters of salinity higher than $30 \%$. The last 2 assemblages were very similar to those found in previous studies with some minor differences (Bousfield et al. 1975, Dodson et al. 1989, Runge \& Simard 1990). Dodson et al. (1989) classified $G$. tigrinus and Crangon septemspinosa in the true-estuarine assemblage. In this study, $G$. tigrinus was reclassified in the tidal freshwater assemblage. C. septemspinosa was characteristic of the trueestuarine assemblage only in July, this species being 
associated with the euryhaline-marine assemblage in June. The change in the distribution of this species is consistent with the spring-early summer up-estuarine migrations observed in other estuaries (e.g. Modlin 1980). Bousfield et al. (1975) also reported greater abundance and biomass for mesozooplankton of the true-estuarine assemblage.

Most importantly, these results support the hypothesis that abiotic variability is a major factor influencing distribution and species diversity of zooplankton in the estuary and that species assemblages are not simply the result of species sorting independently according to their salinity tolerance. Vertical stratification always explained a significant proportion of the variability in species composition and abundance in multivariate analyses. Direct gradient analyses showed that seasonal variations in distribution of the assemblages with respect to salinity was related to variations in $\Delta S / Z$. Furthermore, the limit between the true-estuarine and the euryhaline-marine assemblages, the lowest abundance of large zooplankton and the lowest number of population centers based on the present data set and on the combination of this data set with that of Bousfield et al. (1975) all corresponded to the most vertically stratified waters. In contrast, population centers of all species of the true-estuarine and the euryhalinemarine assemblages were associated with waters that were more homogeneous on the vertical plane (Fig. 4).

A combination of the constraints imposed by the estuarine circulation on the retention of planktonic organisms and the variability in physico-chemical conditions on the vertical plane as proposed by Laprise \& Dodson (1993) is the most parsimonious explanation for the associations observed between vertical stratification, zooplankton distribution and species diversity in the St. Lawrence Estuary. The absence of population centers associated with the most vertically stratified waters suggests that there may be some absolute limit of tolerance to cyclic abiotic fluctuations in planktonic organisms. As vertical migrations are necessary for the retention of zooplankton in these waters (see 'Introduction'), animals must cope with the highest fluctuations of abiotic conditions in the estuary due to the presence of strong vertical gradients in salinity and temperature. For example, an animal that migrates over $20 \mathrm{~m}$ in waters of an average salinity of $18 \%$ early in June would experience an average change in salinity of $14 \%$, every $24 \mathrm{~h}$ in the case of diel vertical migrations (Fig. 4). The observed depression in total abundances of zooplankton and the high species richness of the area may also be explained by vertical stratification. Salinity discontinuities can inhibit diel vertical migrations of zooplankton (Grindley 1964). In salinities corresponding to the most vertically stratified waters of the estuary, Bousfield et al. (1975) and Dodson et al.
(1989) reported that true-estuarine species were mostly associated with the fresher surface waters flowing downstream whereas euryhaline-marine species were found mainly in more saline deep waters flowing upstream, suggesting that animals may be confined in waters that transport them away from the centers of their respective populations. In addition, Bousfield et al. (1975) noted that copepods found in these waters were mostly moribund, non-reproductive animals, suggesting that this habitat may constitute an extreme environment for these species. Consequently, zooplankton abundances may diminish as a result of mortality as animals move away from their population centers, resulting in the lowest abundances of organisms mid-way between the true-estuarine and the euryhaline-marine assemblages. In contrast, the edge effect caused by mixing individuals from the 2 assemblages results in increasing the species richness, with trueestuarine species dominating in salinities closer to $10 \%$ and euryhaline-marine species dominating in higher salinities. Therefore, species richness gives an erroneous impression of the evolution of zooplankton species diversity along the environmental gradient due to the susceptibility of these animals to be transported to unsuitable habitats.

Turbidity and temperature appear to play a minor role in influencing spatial distribution patterns of summer zooplankton in the estuary. No significant relationship was found between turbidity and individual species or total abundances of large zooplankton. Both tidal freshwater and true-estuarine assemblages were found in waters of highest turbidities. In contrast to the hypothesis of Dodson et al. (1989), this suggests that factors controlling the distribution of zooplankton and SPM in the estuary are different. The association between temperature and zooplankton distribution in the multivariate analyses reflects the strong negative correlation existing between temperature and salinity over short periods of time. However, as the season progressed, waters warmed thus decreasing the correlation between salinity and temperature over the seasonal time-scale. The association between zooplankton distribution and temperature decreased accordingly because organisms remained in similar salinities as the season progressed but found themselves in warmer waters. This resulted in the smaller contribution of temperature when all samples of the 2 mo sampling period were included in the discriminant analyses. Temperature may serve as a cue signalling seasonal changes in distribution with respect to salinity in the case of Crangon septemspinosa.

We conclude that environmental variability is a major factor influencing zooplankton distribution and diversity in estuaries, as in the case of other estuarine animals. Zooplankton populations in the St. Lawrence 
Estuary are concentrated in the most abiotically stable parts of the estuary. No species populations' center was associated with the most stratified waters, which was also the site of the lowest zooplankton abundance in the estuary. As such, the large-scale distribution of zooplankton in the St. Lawrence may be considered as primarily physically controlled. However, the confinement of zooplankton populations in restricted areas defined by salinity and vertical stratification may promote strong interspecific interactions. Within these areas, the regulation of zooplankton populations may be more biologically controlled. The sharpest reduction in the abundances of Bosmina longirostris and amphipods occurred at the limit of salt-water intrusion, in salinities they can tolerate. However, these waters also correspond to the upstream limit of the true-estuarine assemblage in which most species may prey heavily on $B$. Jongirostris and amphipods; this includes all life-history stages of fishes (Dauvin \& Dodson 1990 , Laprise 1991, Laprise \& Dodson unpubl. data) and, in the case of $B$. longirostris, most probably mysids (Mauchline 1980, Fulton 1982). In addition, the seasonal decline observed in the abundance of mesozooplankton in the estuary was related to the increase in the abundance of their potential macrozooplanktonic predators, suggesting that predator-prey interactions may be important in structuring these assemblages. The importance of these trophic dynamics in structuring assemblages and controlling secondary production in the estuary is the subject of ongoing research.

Acknowledgements. We thank Jean-Yves Anctil, Caroline Berger, Sophie Bérubé, Katleen Cóté, Michel Dubé, Monique Gagnon, Julie Goulet, Serge Higgins, Alain Kemp, Brigitte Lavoie, Sophie Leclerc and the crew of the MV 'Rigolet' for their help in the field and the laboratory. We especially thank Marie-Claire Baby for processing microcrustaceans. This project was supported by grants from FCAR (Québec) and NSERC (Canada) to J.J.D. and Groupe Interuniversitaire de Recherches Océanographiques du Québec. R.L. was funded by a Department of Fisheries and Oceans (Canada) visiting fellowship.

\section{LITERATURE CITED}

Bousfield, E. L., Filteau, G., O'Neill, M., Centes, P. (1975). Population dynamics of zooplankton in the middle St. Lawrence Estuary. Estuar. Res. 1: 325-351

Collins, N. R., Williams, R. (1982). Zooplankton communities in the Bristol Channel and Severn Estuary. Mar. Ecol. Prog. Ser. 9: 1-11

Dauvin, J. - C., Dodson, J. J. (1990) Relationship between feeding incidence and vertical and longitudinal distribution of rainbow smelt larvae (Osmerus mordax) in a turbid wellmixed estuary. Mar. Ecol. Prog. Ser. 60: 1-12

De Jonge, V. N. (1974). Classification of brackish coastal inland waters. Hydrobiol. Bull. 8: 29-39

Dodson, J. J., Dauvin, J.-C., Ingram, R. G., D'Anglejan, B
(1989). Abundance of larval rainbow smelt (Osmerus mor$d a x)$ in relation to the maximum turbidity zone and associated macroplankton fauna of the Middle St. Lawrence Estuary. Estuaries 12: 66-81

Fortier, L., Leggett, W. C. (1982). Fickian transport and the dispersal of fish larvae in estuaries. Can. J. Fish Aquat. Sci. 39: 1150-1163

Frontier, S. (1969). Sur une méthode d'analyse faunistique rapide du zooplancton. J. exp. mar. Biol. Ecol. 3: 18-26

Frontier, S. (1983). Stratégies d'échantillonnage en écologie. Masson and Presses de l'Université Laval, Québec

Fulton, R. S. III (1982). Predatory feeding of two marine mysids. Mar. Biol. 72: 183-191

Gauch, H. G. Jr (1982). Multivariate analysis in community ecology. Cambridge University Press, New York

Green, J. (1968). The biology of estuarine animals. University of Washington, Seattle

Grindley, J. R. (1964). Effect of low-salinity water on the vertical migration of estuarine plankton. Nature 203: 781-782

Heerebout, G. R. (1970). A classification system for isolated brackish inland waters, based on median chlorinity and chlorinity fluctuation. Neth. J. Sea. Res. 4: 494-503

Holliday, F. G. T. (1971). Salinity: fishes. In: Kinne, O. (ed.) Marine ecology, Vol. 1, Part 2. Wiley-Interscience, London, p. 997-1033

Kinne, O. (1971). Salinity: invertebrates. In: Kinne, O. (ed.) Marine ecology, Vol. 1, Part 2. Wiley-Interscience, London, p. 821-996

Lance, G. N., Williams, W. T. (1967). A general theory of classificatory sorting strategies. I. Hierarchical systems. Computer J. 9: 373-380

Laprise, R. (1991). La rétention des larves d'éperlan (Osmerus mordax) et de poulamon (Microgadus tomcod) dans le bouchon de turbidité de l'estuaire moyen du St-Laurent. Ph.D. thesis, Université Laval, Québec

Laprise, R., Dodson, J. J. (1989). Ontogenetic changes in the longitudinal distribution of two species of larval fish in a turbid well-mixed estuary. J. Fish Biol. (Suppl. A) 35 $39-47$

Laprise, R., Dodson, J. J. (1990). The mechanism of retention of pelagic tomcod, Microgadus tomcod, larvae and juveniles in the well-mixed part of the St. Lawrence Estuary. Environ. Biol. Fish. 29: 293-302

Laprise, R., Dodson, J. J. (1993). Nature of the environmental variability experienced by benthic and pelagic animals in the St. Lawrence Estuary, Canada. Mar. Ecol. Prog. Ser. 94: 129-139

Legendre, L., Legendre, P. (1984). Ecologie numérique, Vol. II, La structure des données écologique, 2nd edn. Masson and Presses de l'Université du Québec, Québec

Legendre, P., Vaudor, A. (1991). Le progiciel R - analyse multidimensionnelle, analyse spatiale. Université de Montréal, Montréal

Mauchline, J. (1980). The biology of mysids and euphausiids. Adv. mar. Biol. 18: 1-681

McLusky, D. S. (1981). The estuarine ecosystem. John Wiley and Sons, New York

Miller, C. B. (1983). The zooplankton in estuaries. In Ketchum, B. H. (ed.) Ecosystems of the world, Vol. 26, Estuaries and enclosed seas. Elsevier Science Publishing Co., New York, p. 103-149

Modlin, R. F. (1980). The life cycle and recruitment of the sand shrimp, Crangon septemspinosa, in the Mystic River estuary, Connecticut. Estuaries 3: 1-10

Ouellet, Y., Cerceau, J. (1976). Mélange des eaux douces et des eaux salées du Saint-Laurent, circulation et salinité Cah. Centreau 1(4): 1-57 
Parry, G. (1966). Osmotic adaptation in fishes. Biol. Rev. 41: $392-444$

Pielou, E. C. (1975). Population and community ecology: principles and methods. Gordon and Breach Science Publishers, New York

Remane, A., Schlieper, C. (1971). Biology of brackish water Wiley Interscience, New York

Runge, J. A., Simard, Y (1990). Zooplankton of the St. Lawrence Estuary: the imprint of physical processes on its composition and distribution. In: El-Sabh, M. I., Silvergerg, N. (eds.) Coastal and estuarine studies, Vol. 39,

This article was submitted to the editor
Oceanography of a large-scale estuarine system: the St Lawrence. Springer-Verlag, New York, p. 296-320

Sanders, H. L. (1969). Benthic marine diversity and the stability-time hypothesis. Brookhaven Symp. Biol. 22 $71-81$

Van Guelpen, L., Markle, D. F., Duggan, D. J. (1982). An evaluation of accuracy, precision and speed of several zooplankton subsampling techniques. J. Cons. int. Explor. Mer 40: 226-236

Vernberg, W. B., Vernberg, F. J. (1972). Environmental physiology of marine animals. Springer-Verlag, New York

Manuscript first received: May 6, 1993

Revised version accepted: January 11, 1994 